Article

\title{
The Mosque and Social Networks: The Case of Muslim Youth in Brisbane
}

\author{
Ameera Karimshah ${ }^{1}$, Melinda Chiment ${ }^{1}$ and Zlatko Skrbis ${ }^{2, *}$ \\ ${ }^{1}$ University of Queensland, St Lucia, QLD 4072, Australia; E-Mails: ameera.karimshah@uqconnect.edu.au (A.K.), \\ melinda@ajaproject.org (M.C.) \\ ${ }^{2}$ Monash University, Clayton Campus, Wellington Road, Clayton VIC 3800, Australia; E-Mail: zlatko.skrbis@monash.edu; \\ Tel.: +613-9902-0214 \\ * Corresponding author
}

Submitted: 13 September 2013 | In Revised Form: 6 May 2014 | Accepted: 6 May 2014 | Published: 20 August 2014

\begin{abstract}
Much of the existing public discourse surrounding Muslim youth in Western societies is framed through a simplistic and static understanding of the role of the Mosque in their everyday life. Mosques are often seen as places for the development of Muslim conservatism where membership is gender and ethno-specific and activities are socially restrictive (Spalek \& Imtoual, 2007, p. 195; Spalek \& Lambert, 2008; Poynting \& Mason, 2008, p. 237). This contributes to an ongoing public preoccupation with the idea that it is necessary to integrate Muslim youth into "mainstream society" as a counter measure to anti-social behaviour and attributed outcomes (i.e. terrorism). This paper, building on the work of Dialmy (2007, p. 70) and Jamal (2005, p. 523), offers an account of how young Muslims network and socialise around the Mosque in Brisbane, Australia. We show that contrary to popular public conception, the role of the Mosque in the lives of Muslim youth is multifaceted and serves as the centrepiece from which the majority of socialisation, across variety formal and informal networks, occurs. This paper also explores the reasons underpinning Muslim youth's social participation, emphasizing the socio-cultural factors (both within and beyond the place of worship) that facilitate and hinder participation across a range of social settings. We argue that discussions on Muslim youth and social engagement must be positioned within an informed understanding of the nuanced role of the Mosque in the generation of social networks within Western contexts.
\end{abstract}

\section{Keywords}

belonging; homophily; mosque; Muslim; social networks; youth

\section{Issue}

This article is part of the special issue "Migrant Youth, Intercultural Relations and the Challenges of Social Inclusion", edited by Professor Fethi Mansouri (Deakin University, Australia) and Dr. Anna Halafoff (Deakin University, Australia).

(C) 2014 by the authors; licensee Cogitatio (Lisbon, Portugal). This article is licensed under a Creative Commons Attribution 4.0 International License (CC BY).

\section{Introduction}

The past three decades has seen a steady rise of Islamophobia in Australia and around the world (Poynting \& Mason, 2008, p. 237; Dialmy, 2007, p. 70; Spalek \& Imtoual, 2007, p. 190; Sirin \& Katsiaficas, 2010, p. 1530). In Australia this sentiment has been fuelled by factors such as the Gulf Wars, the rise of "Middle Eastern crime gangs", media representations of illegal immigrants and the ongoing "war on terror" (Poynting \& Mason, 2008, p. 238, Kabir, 2005, p. 245). As such, re- search pertaining to young Muslims in Western contexts has typically been framed within, or in response to, this discourse (Dunn, Klocker, \& Salabay, 2007, p. 565; Poynting \& Mason, 2008, p. 237; Mansouri \& Wood, 2008, p. 9). This is particularly the case following the events of $9 / 11$, when government policy began to emphasise group accountability; and monitoring of the social activities of certain groups (Spalek \& Imtoual, 2007,2008 , p. 189). This has resulted in an abundance of policies aimed at cultivating social cohesion, the prevention of marginalization and associated negative 
outcomes (e.g. anti-social behaviour, terrorism). These policies have targeted certain ethnic groups; with a particular interest in Muslim youth both in Australia and internationally (DIAC, 2012; UK Department of Communities and Local Government, 2012). In addition, media outlets continue to present an often negatively biased view of the Muslim communities in Western contexts (Byng, 2010, p. 109; Saeed, 2007, p. 443).

The importance of religious institutions in the reception and resettlement of migrants is not limited to Muslims. Indeed, Wilson (2011, p. 549) illustrates how Christian groups use the concept of faith-based hospitality to challenge public discourse and provide services to asylum seekers in Australia, while Foley and Hoge (2007, p. 24) assess the role of religious institutions in promoting civic engagement among recent immigrants to the US. Both studies found that for migrants, membership in a place of worship not only serves religious needs but plays an important role in providing social connections in an unfamiliar environment. Furthermore, as our research will demonstrate, the role of the place of worship in providing social connections for migrants extends beyond the first generation. For both first and second generation Muslim youth in Brisbane involved in this research, the mosque permeates all aspects of young people's social lives.

Inherent within dominant conceptualizations of Muslim youth and social engagement, is a characteristically static understanding of how and why young people form networks. Unfortunately, the dominant narratives that shape public perceptions are often the result of an emphasis on extreme cases. An insularity of networks, gender and ethno-specific exclusivity, poor levels of civic engagement and political mobilization are typically underscored in these cases (see, for example, Jasser, 2011; O'Duffy, 2008). Arguably, these simplistic understandings of youth engagement, particularly in the mosque, fuel ongoing preoccupations with negative stereotypes about Muslim youth and perpetuate public misconceptions about the Muslim community more broadly. The data presented herein, illustrate the effects of wider public discourse on social engagement among Muslim youth.

Despite this often simplistic understanding of Muslim youth and social networks, emerging research from scholars such as Dialmy (2007, p. 71), Modood and Ahmad (2007, p. 190) and Annette (2011, p. 391), offer a different perspective on ways in which young Muslims network and socialize within predominantly Western contexts. This paper further explores the reasons for engagement, emphasizing the socio-cultural factors (both within and beyond the place of worship) which facilitate and/or hinder participation for Muslim youth across a range of settings. Our paper focuses on young people's participation in the mosque and we argue that discussions pertaining to Muslim youth and their social participation must be positioned within an informed understanding of how social and practical contexts impact the type and extent of network involvement. The mosque continues to be an important organisational entity within the Muslim community, specifically in secular societies (Dialmy, 2007, p. 73). Indeed, as illustrated in the findings presented below, and contrary to dominant public perception, the role of the mosque is multifaceted and ultimately serves as the centrepiece from which the majority of socialisation, across formal and informal networks occurs.

\section{Conceptual Framework}

Conceptually, our interrogation of networking among Muslim youth will be discussed using the framework of homophily and heterophily. The principle of homophily, also known as the "like me" hypothesis (Laumann, 1966, p. 40), states that social interactions and subsequent network formation are more likely to occur between those individuals who share socio-demographic, behavioural and interpersonal characteristics than between those who do not (Lazerfeld \& Merton, 1954, p. $55)$. The principle of homophily initially emerged as an extension from the classical work of Homans (1951, p. 108) on relationship dynamics within small primate groups. Through observation, Homans discovered that the more time the members of these primate groups spent with one another, the more sentiment they shared. Likewise, the more sentiment they shared, the more time they spent together. As these reciprocal processes increased in frequency, so too did the members' tendency to engage in collective, mutually benefiting activities (Homans, 1951, p. 108; Homans, 1961, p. 191). This process has been labelled the "sentimentinteraction" hypothesis.

Since the classical work of Homans, the principle of homophily has been used to explain a range of social phenomena from internet usage (see Steffes \& Burgee, 2009 , p. 43) to peer bullying (see Dijkstra, Lindenberg, \& Veenstra, 2007, p. 1377). Yet, regardless of the specific social phenomena to which the principle of homophily is applied, the core thesis remains. That is, similarity breeds connection. Recent research consistently confirms this, identifying age (Kiesner, Poulin, \& Nicotra, 2003, p. 1341; McPherson, Smith-Lovin, \& Cook, 2001) and gender (Hodgkin, 2008, p. 306; Maccoby, 1998) as highly salient types of homophilous interactions. Above all else however, race and ethnicity continue to constitute the most prevalent types of homophily (McPherson et al., 2001, p. 424; Mollica, Gray, \& Trevino, 2003), constituting the largest divide between people's social networks (see Ibarra, 1995, p. 675; Kalmijn, 1998, p. 406; Newman \& Dale, 2007, p. 82 ). For young people from migrant backgrounds homophilous interactions are prevalent, particularly considering the common geographic concentration of migrant groups (Portes \& Zhou, 1993, p. 80) combined 
with the impact of exclusionary practices or negative discourses perpetuated from the dominant host country population.

Given the above, one would expect young Muslims in Brisbane with close geographic proximity, frequency of interaction through religious practices, and exposure to negative public discourse, to form and engage in highly homophilous networks. Indeed, it is this assumption which arguably fuels much of the anxiety surrounding Muslim youth. Yet, our findings reveal that while young people's networks are homophilous, network formation and engagement does not fully play out in the way one might expect. In fact, despite common assumptions of the role of the mosque in creating and shaping homogenous membership, Muslim youth engage in a range of activities within the context of the mosque and affiliated networks. This finding challenges our understanding of the impact of homophilous network engagement broadly and the impact for Muslim youth, specifically.

Using the principle of homophily to frame analysis and discussion, this paper will explore the ways Muslim youth engage within and around their place of worship. Specifically, we examine both the types of formal and informal networks in which youth are involved as well the intrinsic and extrinsic factors that shape network choices. Following a description of research methods, we will progress a discussion of the role of culture in religious participation for Muslim youth in Brisbane. We offer an account of the networks of young people, particularly the positioning of the mosque as a centrepiece from which young people's networks emerge. Subsequently, through an analysis of the barriers to external participation for young people, we suggest that experiences with implicit and explicit racism and discrimination reinforce the role of the mosque for young people in hostile social climates. Lastly, we examine young people's perceptions of existing network limits.

\section{Research Methods}

The data presented herein are derived from the Australian Research Council Linkage project "Social Networks, Belonging and Active Citizenship among Migrant Youth in Australia". ${ }^{1}$ The project, sought to investigate the extent to which young people from diverse backgrounds participate in formal and informal networks to develop a sense of belonging in Australia. Research sites included Melbourne and Brisbane and data collection consisted of surveys, qualitative interviews and fo-

\footnotetext{
${ }^{1}$ ARC LP0989182, Mansouri, F., Skrbis, Z., Guerra, C. (Centre for Multicultural Youth), and Francis, S. (The Australian Red Cross). This project focuses on youth from three Australian migrant communities at the centre of recent debates about migrant integration, intercultural conflict and social cohesion: African, Arabic-speaking and Pacific-Islander.
}

cus groups with city-specific service providers. Findings in this paper were limited to in-depth interviews with thirteen first- and second-generation Arabic-speaking young people in Brisbane, aged 15-23. Of these, 11 participants identified as Muslim and two identified as Christian. As this paper is specifically focused on the role of the mosque, these two participants were excluded in the discussion below. Of the 11 Muslim participants, three were born in Australia and the remaining eight had lived in Australia for 8 years or more. It should also be noted that two of the participants had lived in Canada before migrating to Australia. The participants came from a variety of cultural backgrounds including, Egyptian, Lebanese and Iraqi.

Interviewees were recruited via snowball sampling and interviews were conducted by research assistants who themselves identified as Muslim and were actively involved in the Muslim community in Brisbane. Throughout interviews, young people were asked to reflect on the extent of their involvement in formal (e.g. school, religious, government) and informal (e.g. peer groups, social media, informal activities) networks in Australia, with an emphasis on locally-based networks. Subsequently, participants were asked questions to elucidate the relationship between involvement in said networks and feelings of inter-and intra-group belonging. This component touched on issues of alignment of values, the implications for network choices, intergenerational and "community" issues, etc. Lastly, participants were asked to reflect on the practical underpinnings for network choices, primarily the ease in which they negotiate different social settings. This last component raised issues such as location of networks and knowledge of different social gatherings.

\section{The Role of Culture in Religious Participation}

As mentioned above, participants in this project all identified as Arabic-speaking. While there are no statistics on mosque participation in Australia, statistics from the US show that in the Muslim community Arabic-speaking migrants have the third highest level of mosque participation and are more politically active and have greater group consciousness as a result of this participation (Jamal, 2005, p. 524; Bagby, Perl, \& Froeble, 2001, p. 29). Given that recent political attention has focused on religion rather than ethnicity, the mosque plays a key role in collectivising and highlighting the common struggles of all Muslims in mainstream society (Modood \& Ahmad, 2007). Indeed, studies from the UK (Modood \& Ahmad, 2007, p. 199) and the US (Naber \& Arbor, 2005, p. 479) have shown that young migrants are increasingly giving saliency to religion rather than ethnicity as a form of collective identity. Participants in this project also saw themselves primarily as Muslim, identifying more strongly with Islam then with their cultural background. This is exemplified by one participant below: 
For me, it doesn't really matter where I come from; it's what my religion is [...] (Female, Age 21)

In all conversations about networks, participants referred more often to religion than culture and sometimes used the two interchangeably. When asked if culture influenced her network involvement one participant explained:

I think so, yes. Because my culture is linked in with Islam because obviously I think Arabs and so on. (Female, Age 20)

For participants, both formal and informal networks were identified as Islamic or Muslim. Although there were some informal cultural groups, these too were composed of only Muslims. This is consistent with previous research that illustrates how Muslims in the west, specifically youth, often take on a more universalist orientation toward Islam (Dialmy, 2007, p. 73) as they lose their connection with their homeland or the homeland of their parents. Creating an identity around religion rather than ethnicity allows young people to belong to a community without the restraints of physical space. Furthermore, the boundaries of religious identity are much more clear-cut and pervasive in comparison to ever changing and mixing ethnic boundaries (Jacobson, 2010, p. 240).

\section{How and Why Young Muslims Formed Networks}

Although the participants in this research were involved in a number of different types of networks, these networks were largely homophilous: members shared similar socio-economic, religious and ethnic characteristics. There was also much interlinking between formal and informal networks. Participants interacted with people from their formal networks outside of these groups and some became involved with formal groups through their informal networks. Again, despite the range of networks and activities in which young people were involved, the networks were arguably homophilous, generating bonding social capital for network members. Our research suggests that one reason driving the formation and engagement in homophilous networks for Muslim youth is the significant role of the mosque in generating networks.

The young people involved in this research reported that the mosque was a place where both formal and informal networks are established and negotiated. This is consistent with previous research confirming that while in predominantly Muslim countries it is sufficient for the mosque to serve simply as a place of worship; this role alone is insufficient to the needs of migrant communities in secular societies (Dialmy, 2007, p. 73). Participation in the place of worship has instead become a means for the individual to affirm their identity within the host society through socialisation (Dialmy, 2007 , p. 73). With the exception of professional and educational institutions, the majority of activities that the participants were involved in were religiously affiliated, generated by and sustained through engagement with their place of worship. These networks, the way they were formed, maintained and interlinked are discussed below.

All participants involved in this research actively participated in mosque activities. Yet, the frequency of attendance and the type of engagement varied with age. The school-aged participants attended religious classes at the mosque two to three times per week. These classes included, but were not limited to, Qur'an reading, Arabic lessons and Islamic history. In addition to learning, the young people also saw these classes as an opportunity to socialise with their existing friends and to make new ones. This was particularly true and important for recent migrants, for whom involvement in these activities provided an inclusive space where new relationships could be cultivated. The pattern of mosque engagement differed for the older participants who attended the mosque primarily for prayers, lectures and social events such as fundraisers. While some events were organized specifically to encourage participation by young people, others were targeted towards the wider community. The mosque was seen as something all Muslims have in common, a place where Muslims were welcome. As one participant described:

The mosque is a common trait a [...] common place that we all go to. (Male, Age 23)

For participants in this research, the mosque was a unifying space which facilitated the forming of other networks. Indeed, socialisation was not limited to those activities which occurred within the mosque. For example, friendship networks were often facilitated by mosque attendance. One participant spoke about meeting his friends at the mosque every week for Friday prayers and then collectively going out for lunch afterward. There was no need to invite anyone or discuss the location of these lunches beforehand because mosque attendance was assumed and a mutual decision could be made on the day. The participants were also involved in a number of formal activities in which religious affiliation played an important role in determining participation. This included Muslim student associations, youth groups, advocacy groups, charities and women's groups. The composition of these groups was entirely Muslim and often initiated by youth. The frequency of participation in these groups varied, some participated occasionally when there was a special event and others participated regularly, by attending meetings and helping to run the organisation. Despite the variations between these groups and their activities, they shared a common feature: they have arisen 
from within the mosque context.

This research suggests that a range of practical and social factors influenced young people's engagement which was both internally and externally derived: that is, some factors came from both within their own group as well as a response to mainstream influences. Practical reasons included convenience and ease of access. As one participant explained:

Well the mosque I go to is my local mosque so I go there because it's close and because everyone-a lot of people I know live in this area and we all just go to that mosque. (Male, Age 23)

In many ways, this research confirms findings from the broader homophily literature regarding the role of geography in shaping people's networks. For young Muslims in Brisbane, spatial proximity of mosque-related networks was an influential factor in the frequency of young people's meetings.

The mosque also played an important role in the decision to join networks in non-religious settings. For many participants, mosque was seen as a centrepiece for outward engagement in a non-religious setting. This was illustrated by one participant who was an active member of a political party and explained his reasons for joining as follows:

[...] a political network who shares a lot of the same views as us originally in the past, with helping us to build a mosque. So I definitely affiliate myself with them. I got involved with them and I helped them out. (Male, Age 21)

Another example was in places such as school and university, participants tended to seek out other Muslims to interact with. Their ability to group themselves with other Muslims was seen positively as they felt the interaction was easier, due to shared values and norms as well as a mutual understanding of the expectations for engagement. In describing this dynamic, one participant said:

Like going out with some of your non-Muslim friends to clubs or when they get together and drink and stuff. You never really feel comfortable going or it's not the same as you would feel with your own group of friends. (Male, Age 21)

As illustrated in our findings, the mosque, while highly homophilous, served as a facilitator of a range of other networks for young Muslims in Brisbane. From engagement and connections within the mosque, young people formed political, extra-curricular and schoolrelated networks. In many ways, this finding challenges dominant assumptions of the mosque as an anti-social space and reveals that the mosque plays a central role in facilitating young people's engagement in a variety of formal and informal networks.

As a reaction to wider Australian culture and influence, participants described feeling a sense of security fostered through their homophilous networks. For some, interacting with other Muslims ensured, not only that they would not have to explain their religiousbased practices but also would not be influenced or pressured into doing anything that is un-Islamic. This perceived sense of security had a gendered element as well. For female participants, the need for this kind of security appeared to be more prevalent and urgent. This stemmed from both their personal desire to ensure a positive influence from their networks as well as a way to alleviate parental concerns thus allowing them more freedoms. This is illustrated by one participant who explained:

Yes, if there's a group that's Muslim and they're mostly girls, then it would encourage us more to be a part of them, because the thing is we would assume that they would stay away from haram. (Female, Age 20) (Anything that is forbidden in Islam is haram)

As described in the preceding section, young people in this research face numerous internal and intragroup factors which influence their participation in largely homophilous networks. The following section explores networks formation and engagement from a different perspective, analysing the external and inter-groups factors which underpin and influence young people's network choices. As will be discussed, for many young people influence from within their community as well as external exclusionary practices and exposure to racism and discrimination creates a further reliance on the mosque to meet young people's social needs.

\section{The Effect of Racism and Discrimination on Network Choices}

While young Muslims participated in a range of activities and networks, these networks themselves were overwhelmingly homophilous. As described above, there were a variety of internal reasons for engagement in homophilous networks. There was also some evidence, however, that network preferences and practices were compounded by broader exclusionary forces and mechanisms, often functioning as actual and perceived barriers to external social participation. In this case there were comparatively more social barriers than practical, although some practical barriers did exist. The most common social barrier identified by participants was instances of explicit and implicit racism and discrimination. Barriers to participation were also linked to internal pressures from within their own communities. The section below will examine these two instances more closely. 
Specific incidences of racism and discrimination mostly involve being singled out based on appearance and ethnicity. Our research shows that this occurred across a range of settings and in various ways. Some participants reported the immediate distance and exclusion that they felt by being asked the question "where are you from?" According to participants, this made them feel as though being judged as "unAustralian" based on their appearance. Other incidences of racism and discrimination involved being singled out in a group based on appearance and ethnicity. This is exemplified in the following quote:

Yeah, because nearly every girl I know that wears a headscarf has had racism and it would be a lie, if I said it wouldn't affect you because it does. You feel like what if it happens again or whatever, do you know? (Female, Age 18)

Incidences of racism were not always explicit or limited to verbal abuse. Participants described it as the way someone looked at them or a feeling they got. One participant describes having this kind of tension with his volleyball coach:

Nothing direct, like name calling or group labelling, nothing direct. But there was always that feeling that there was prejudice and a bit of, I don't know, yeah, you never felt-I never felt accepted with that guy. There was always something different between me and the other players in the team. (Male, Age 21)

Findings from our research indicate that young people's experience with implicit and explicit discrimination and/or racism led to further dependence on the mosque and affiliated networks as a means to cope with said experiences and also fulfil social needs in the face of wider social exclusion. Again, while for many young people, exclusive engagement in mosque-related activities was driven by intrinsic and intra-groups forces, for others, engagement was reinforced by exposure to racism and a need to avoid potentially hostile social spaces.

Research participants also indicated that they faced several internal barriers to external participation. For example, they discussed elements of their religion that limited their interactions with heterophilous networks. As one young woman described:

At uni obviously I have friends and they're not Muslim obviously, but they might invite me over to places which I don't go because there's alcohol, or there's partying or whatever, so that affects how much I interact with them and who I'm interacting with. So I can have uni colleagues, but I wouldn't take it any further. Even at school it was like that. (Female, Age 21)
Amongst the female, participant's gender was an issue that magnified and compounded some of the other barriers described above. They felt that their differences were more obvious because their hijab and were more prone to racism and discrimination.

Sometimes you get looks you know, what she's wearing [...]. (Female, Age 15)

The female research participants also felt that their families and communities were more protective of them and therefore placed more barriers in front of them especially when it came to interacting with the opposite sex.

Yes if there's guys there can't really join it. [...] Religious reasons [-] religious and cultural reasons, [yeah just] expected not to do it. (Female, Age 16)

As described above, for young women in our research, the ability to join wider social networks was further restricted due to gender-specific considerations. For some, the decision to engage exclusively in female Muslim networks was a personal choice. That is, young women made the choice to limit networks as a way to reduce uncertainties and risks associated with nonMuslim youth. For others, network choices were influenced, or controlled, by parents or members of the Muslim community.

Participants in this group experienced notably fewer practical barriers than social. The practical barrier most mentioned was unfamiliarity or lack of knowledge of social networks. One participant said:

More so the unfamiliarity with the group. Yeah, I like to go to things where I kind of know my way around and know the people involved. If it's something new or something I don't know anything about, then yeah, I feel a bit uncomfortable and wouldn't be too fond of joining up a group if like that. (Male, Age 21)

Other barriers that were mentioned include distance, lack of time and/or money and language problems. However these were only mentioned by one or two participants.

Findings demonstrate that social and practical barriers to wider social participation, as experienced by young people, had a significant impact on their desire and ability to expand their social networks. Incidences of racism and discrimination and uncertainties regarding social expectations and norms challenged young people's sense of belonging within non-mosque related networks. As a result, young people restricted their exposure to and participation in non-Muslim networks as a defence mechanism and relied more heavily upon their existing networks to meet their social and emo- 
tional needs. Again, while this reinforced engagement in mosque-related networks, the networks themselves, as described above, were quite diverse.

\section{Limits to Networking}

Although the networks facilitated by and through the mosque provided the participants with a safe and comfortable environment for them to be involved in, participants also described several limits that it imposed. Accordingly, certain activities were not actively encouraged. For example, access to the arts was limited within the Muslim community in Brisbane, with hardly any related activities being advertised or encouraged through the mosque or other religiously affiliated networks. As one young woman stated:

Yeah, because in the Muslim community, unfortunately they don't have a lot of attention towards arts and crafts and arts and music. I think it's because they really focus on, my kids have to be lawyers, they have to be engineers, they have to be-you know, all that really high expectations, like with professions. To the extent that they actually forget the artistic side of the child that actually the child can have, which can be really positive. (Female, Age 23)

Sporting activities for young girls is another example of an activity that was not encouraged or supported by the mosque. While many male participants were involved in both formal and informal sporting activities, for girls, sporting activities were limited to the informal realm. This was partly due to the lack of organized teams within their existing networks and partly due to an inability to participate in mainstream teams due to clothing requirements. In describing his sister's situation one participant explained:

My sister was a tennis player but because the Australian Tennis Federation says you gotta stick to a particular clothing attire, so she couldn't wear the scarf and girls aren't meant to wear pants. (Male, Age 21)

These limits were not seen as overly problematic given that the majority of the needs were met through the mosque and affiliated organisations. For most Muslim youth, networks were seen as an effective way of meeting their needs albeit with room for diversification.

\section{Discussion and Conclusion}

Findings from this research demonstrate the significant role of the mosque in the lives of Muslim youth in Brisbane. In line with previous research (Dialmy, 2007, p. 73; Modood \& Ahmad, 2007, p. 194, Annette, 2011, p. $391)$, the mosque served not only as a religious institu- tion but as a centrepiece for socialisation and the creation and maintenance of other networks. Participants in this project were involved in a variety of activities that were largely made up of other Muslims and had stemmed from existing networks within the mosque. This was arguably a result of both practical and social factors related to ease of access and shared understandings. It provided young people with a sense of security, in that they did not have to defend their religion or explain their practices. Furthermore they were not at risk of being pressured or influenced to do anything that was un-Islamic. These mosque-affiliated networks played a critical role in meeting the social and emotional needs of participants but were not without their shortfalls. Certain activities that were desirable to the young people were not readily available to them due to their perceived inability to outwardly engage. Additionally, many activities that were not organized or supported by the mosque or other religiously affiliated organizations were not easily accessible to the young people. Muslim young people in this research also experienced high levels of racism and discrimination which inhibited their desire to network outwardly.

As a result of the many social and practical factors which influence network involvement and the significant role of the mosque in serving as the centrepiece from which social networks emerged, the networks in which young Muslims engaged are highly homophilous. Indeed, as illustrated by our findings, for young people in Brisbane the mosque is an institution that facilitates homophilous networks both formally and informally. Young people's networks were highly homophilous with regards to geographic proximity of members, ethnicity, kin ties, inter-personal and behavioural characteristics. Indeed, as illustrated through the experiences of Muslim youth in Brisbane, we see that the role of the mosque is multifaceted, ultimately serving as the centrepiece from which the majority of socialisation, across formal and informal networks occurs. Additionally, and contrary to popular discourse, these homophilous networks did not produce a homogenous community or engender antisocial sentiment but rather enabled young people to engage in a variety of social and civic activities. In fact, our findings demonstrate that mosque is a reflexive space that catered for a variety of interests and generated a diversity of networks. In exploring the way in which young people negotiated their networks and thought about the spaces in which they lived, this paper has sought to challenge the stereotypes about young Muslims and the role of the mosque in their everyday lives.

\section{Acknowledgements}

This paper is based on research undertaken as part of the Australian Research Council Linkage project (LP0989182) titled "Social Networks, Belonging and ACtive Citizenship among Migrant Youth in Australia". 
This was a collaborative project involving Deakin University, Monash University, The Centre for Multicultural Youth and The Australian Red Cross.

\section{Conflict of Interests}

The authors declare no conflict of interests.

\section{References}

Annette, J. (2011). Faith communities, communitarianism, social capital and youth civic engagement. Ethnicities, 11(3), 383-397.

Bagby, I., Perl, P. M., \& Froeble, B. T. (2001). The Mosque in America: A National Portrait. Washington, DC: Council on American-Islamic Relations.

Byng, M. D. (2010). Symbolically Muslim: Media Hijab and the West. Critical Sociology, 36(1), 109-129.

Department of Immigration and Citizenship (DIAC). (2012). Diversity and social cohesion program. Retrieved from: www.immi.gov.au/living-in-australia/ delivering-assistance/government-programs/dscp

Dialmy, A. (2007). Belonging and institution in Islam. Social Compass, 54(1), 63-75.

Dijkstra, J. K., Lindenberg, S., \& Veenstra, R. (2007). Same-gender and cross-gender peer acceptance and Peer rejection and their relation to bullying and helping among preadolescents: Comparing predictions from gender-homophily and goal-framing approaches. Developmental Psychology, 43(6), 13771389.

Dunn, K. M., Klocker, N., \& Salabay, T. (2007). Contemporary racism and Islamophobia in Australia. Ethnicities, 7(4), 564-580.

Foley, M., \& Hoge, D. R. (2007). Religion and the New Immigrants: How Faith Communities Form Our Newest Citizens. Oxford: Oxford University Press.

Hodgkin, S. (2008). Telling it all: A story of women's social capital using a mixed methods approach. Journal of Mixed Methods Research, 2(4), 296-316.

Homans, G. C. (1951). The Human Group. London: Routledge \& Kegan Paul.

Homans, G. C. (1961). Social Behaviour: Its Elementary Forms. New York: Harcourt, Brace \& World.

Ibarra, H. (1995). Race, opportunity, and diversity of social circles in managerial networks. The Academy of Management Journal, 38(3), 673-703.

Jacobson, J. (2010). Religion and ethnicity: Dual and alternative sources of identity among young British Pakistanis. Ethnic and Racial Studies, 20(2), 238256.

Jamal, A. (2005). The political participation and engagement of Muslim Americans: Mosque involvement and group consciousness. American Politics Research, 33(4), 521-554.

Kabir, N. A. (2005). Muslims in Australia: Immigration, Race Relations and Cultural History. London/New
York/Bahrain: Kegan Paul.

Kalmijn, M. (1998). Intermarriage and homogamy: Causes, patterns, trends. Annual Review of Sociology, 24(24), 395-421.

Kiesner, J., Poulin, F., \& Nicotra, E. (2003). Peer relations across contexts: Individual-network homophily and network inclusion in and after school. Child Development, 74(5), 1328-1343.

Laumann, E. O. (1966). Prestige and Association in An Urban Community: An Analysis of An Urban Stratification System. Indianapolis: Bobbs-Merril.

Lazerfeld, P., \& Merton, R. (1954). Friendship as A Social Process: A Substantive and Methodological Analysis. In P. L. Kendall (Ed.), The Varied Sociology of Paul F. Lazerfield (pp. 298-348). New York: Columbia University.

Maccoby, E. E. (1998). The Two Sexes: Growing Up Apart, Coming Together. Cambridge: Harvard University Press.

Mansouri, F., \& Wood, S. P. (2008). Identity, Education and Belonging: Arab and Muslim Youth in Contemporary Australia. Carlton, Victoria: Melbourne University Press.

McPherson, M., Smith-Lovin, L., \& Cook, J. M. (2001). Birds of a feather: Homophily in social networks. Annual Review of Sociology, 27(1), 415-444.

Mollica, K. A., Gray, B., \& Trevino, L. K. (2003). Racial homophily and its persistence in newcomers' social networks. Organization Science, 14(2), 123-136.

Modood, T., \& Ahmad, F. (2007). British Muslims perspectives on multiculturalism. Theory Culture Society, 24(2), 187-213.

Naber, N., \& Arbor, A. (2005). Muslim first, Arab second: A strategic politics of race and gender. The Muslim World, 95(4), 479-495.

Newman, L., \& Dale, A. (2007). Homophily and agency: Creating effective sustainable development networks. Environment, Development and Sustainability, 9(1), 79-90.

Portes, A., \& Zhou, M. (1993). The new second generation: Segmented assimilation and its variants. Annals of the American Academy of Political and Social Science, 530(1), 74-96.

Poynting, S., \& Mason, V. (2008). The new integrationism, the state and islamophobia: Retreat from multiculturalism in Australia. International Journal of Law, Crime and Justice, 36(4), 230-246.

Saeed, A. (2007). Media, racism and Islamophobia: The Representation of Islam and Muslims in the Media. Sociology Compass, 1(2), 443-462.

Sirin, S. R., \& Katsiaficas, D. (2010). Religiosity, discrimination and community engagement: Gendered pathways of Muslim American emerging adults. Youth and Society, 43(4), 1528-1546.

Spalek, B., \& Imtoual, A. (2007). Muslim communities and counter terror responses: "Hard" approaches to community engagement in the UK and Australia. 
Journal of Muslim Minority Affairs, 27(2), 185-202.

Spalek, B., \& Lambert, B. (2008). Muslim communities, counter-terrorism and de-radicalisation: A reflective approach to engagement. International Journal of Law, Crime and Justice, 36(4), 257-70.

Steffes, E. M., \& Burgee, L. E. (2009). Social ties and online word of mouth. Internet Research, 19(1), 4259.

UK Department of Communities and Local Govern- ment. (2012). Bringing people together in strong united communities. Retrieved from www.gov.uk/ government/policies/bringing-people-together-instrong-united-communities

Wilson, E. (2011). Much to be proud of, much to be done: Faith-based organizations and the politics of asylum in Australia. Journal of Refugee Studies, 24(3), 548-556.

\section{About the Authors}

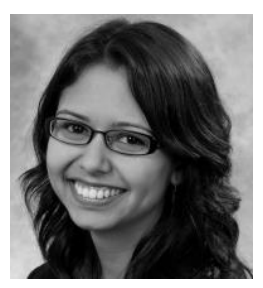

\section{Ameera Karimshah}

Ameera Karimshah has a Master in International Community Development from Victoria University. She was a research assistant on the Australian Research Council Linkage project "Social Networks, Belonging and Active Citizenship among Migrant Youth in Australia" as described herein.

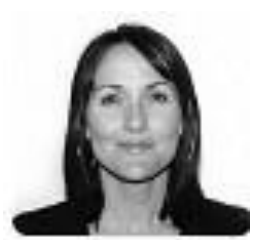

\section{Dr. Melinda Chiment}

Melinda Chiment graduated from the University of Queensland in 2013 with her PhD in Sociology. She was a research assistant on the Australian Research Council Linkage project "Social Networks, Belonging and Active Citizenship among Migrant Youth in Australia" as described herein. She is currently the Director of Program Development at The AjA Project in the US.

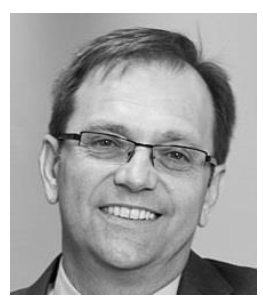

\section{Dr. Zlatko Skrbis}

Zlatko Skrbis is Professor of Sociology in the School of Social Sciences and Vice-Provost (Graduate Education) at Monash University. His research focuses on the question of identities in transition, culture and migration. He is the author of four books: Long-distance Nationalism, 1999, Constructing Singapore (with Michael Barr, 2008; translated into Arabic, 2013), The Sociology of Cosmopolitanism (with Kendall and Woodward), and The Uses of Cosmopolitanism (with lan Woodward, 2013). 